\title{
Elemental and topographic characterization of LDPE based copolymeric films obtained by gamma irradiation
}

\author{
L.M. Ferreira ${ }^{a, *}$, A.N. Falcão ${ }^{\text {a }}$, M.H. Gil ${ }^{b}$ \\ ${ }^{a}$ Department of Physics, Nuclear and Technological Institute, E.N 10, 2686-953 Sacavém, Portugal \\ ${ }^{\mathrm{b}}$ Department of Chemical Engineering, Faculty of Science and Technology, University of Coimbra, Pólo II - Pinhal deMarrocos, \\ 3030-290 Coimbra, Portugal
}

Available online 5 September 2007

\begin{abstract}
The preparation of PE-g-HEMA (polyethylene-grafted-hydroxyethyl methacrylate) films by ${ }^{60}$ Co gamma irradiation has been optimized to produce a new material suitable for bioapplications.

This paper reports the elemental and topographic analysis of PE-g-HEMA films with different grafting degrees, obtained under optimized experimental conditions, with the purpose to appraise their possible toxicological risk and their surface roughness properties.

In this way a Nuclear Microprobe using PIXE (Proton Induced X-ray Emission) technique was used to assess the elemental analysis of the film samples prepared. Trace contaminations of elements heavier than $\mathrm{Si}(\mathrm{Ca}, \mathrm{Cl}, \mathrm{Fe}, \mathrm{K}, \mathrm{P}, \mathrm{S}, \mathrm{Si}$ and $\mathrm{Zn}$ ) were found, but their concentrations do not pose toxicological risk.

Atomic Force Microscopy (AFM) and Scanning Electronic Microscopy (SEM) techniques were used to assess the morphological characterization of the films, revealing the roughness and 3D porous structure of their surface, which are ones of essential characteristics for bio-interaction or cell adhesion.
\end{abstract}

(C) 2007 Elsevier B.V. All rights reserved.

PACS: $28.52 . \mathrm{Fa} ; 82.35 . \mathrm{Jk} ; 82.50 . \mathrm{Kx} ; 82.80 . \mathrm{Ej} ; 68.37 . \mathrm{Hk} ; 68.37 . \mathrm{Ps}$

Keywords: Graft copolymers; Gamma radiation; Polymers for bioapplications; Polymer elemental and topographic characterization

\section{Introduction}

The selection of materials for bioapplications requires proper considerations of its mechanical, physical and biological properties, and very rarely one finds a single natural or synthetic material with all the adequate properties. The development of new materials by manipulating their molecular structure by means of gamma or high-energy electrons irradiation has been proved to be successful in producing materials with adequate surface and bulk properties, which make their use promising notably for medical implant

\footnotetext{
* Corresponding author. Tel.: +351 21994 6066; fax: +351 219941525. E-mail address: ferreira@itn.pt (L.M. Ferreira).
}

devices. These techniques are being used with increasing success with polymeric based systems [1].

To adequate the material for bioapplications (health and environment), the molecular structures of the precursors are generally modified to improve mechanical resistance, hemocompatibility, hydrophylicity and bio-interaction ability (cell adhesion and/or proliferation) [2]. Important questions to address are: (i) once implanted or when in contact with body fluids the new polymeric material can be toxic? How clean and safe is it? (ii) Is the material surface adequate for the required application? To answer these questions a careful characterization of the new material is necessary.

In our studies, using 2-hydroxyethyl methacrylate (HEMA) as grafting monomer, we have optimized the preparation of new grafted copolymeric Low Density 
Polyethylene (LDPE) based films by means of ${ }^{60} \mathrm{Co}$ gamma irradiation. These copolymeric films developed show, at a macroscopic scale, a homogeneous graft distribution (independent of the grafting degree) reaching hydration levels up to $95 \%[3,4]$.

In this work stage the characterization of these films was done using Nuclear Microprobe (NM), Atomic Force Microscopy (AFM) and Scanning Electron Microscopy (SEM). These techniques reveal to be very important for their elemental and topographic characterization. Elemental analysis performed by Nuclear Microprobe using PIXE (Proton Induced X-ray Emission), allowed evaluation of the toxicological risk in the possible uses of the new films, while AFM and SEM techniques revealed the topography and 3D porous structure of the polyHEMA grafted surface that grows over the LDPE matrix film. Morphological analysis was important to inform about polyHEMA grafted chain scission processes, which may occur with increasing radiation dose above a certain threshold [3].

\section{Experimental}

\subsection{Materials}

PE-g-HEMA copolymeric films grafted at $237 \%$ $(d=46 \mu \mathrm{m}), 403 \% \quad(d=73 \mu \mathrm{m}), 166 \% \quad(d=40 \mu \mathrm{m})$ and $163 \%(d=38 \mu \mathrm{m})$, were obtained by mutual gamma irradiation method (in the absence of air) at a dose rate (DR) of $0.3 \mathrm{kGy} \mathrm{h}^{-1}$, during $25 \mathrm{~h}(D=7.5 \mathrm{kGy}), \quad 30 \mathrm{~h} \quad(D=$ $9.0 \mathrm{kGy}), 35 \mathrm{~h}(D=10.5 \mathrm{kGy})$ and $40 \mathrm{~h}(D=12.0 \mathrm{kGy})$, respectively, using a $[\mathrm{HEMA}]_{i}=15 \%(\mathrm{~V} / \mathrm{V}$ in methanol). Details of the experimental preparation conditions can be found elsewhere $[3,4]$.

The matrix used for the grafting process was bioriented film of LDPE ( $\rho=0.920 \mathrm{~g} \mathrm{~cm}^{-3}$ ) with $15 \mu \mathrm{m}$ of thickness commonly used for food packaging applications.

Fig. 1 shows a piece of LDPE matrix and the four grafted films analyzed.

The irradiation experiments were performed at the Portuguese ${ }^{60} \mathrm{Co}$ Facility (UTR) installed at the Nuclear and Technological Institute (ITN), in Lisbon.

\subsection{Samples characterization}

\subsubsection{Nuclear microprobe techniques}

Analyses were performed with a Nuclear Microprobe using simultaneously the techniques of PIXE (Proton Induced X-ray Emission), RBS (Rutherford Backscattering Spectrometry) and STIM (Scanning Transmission Microscopy). A $2 \mathrm{MeV}$ energy proton beam focused to $3 \times 4 \mu \mathrm{m}^{2}$, with beam currents of about $200 \mathrm{pA}$ was used. Scanning proton beam amplitudes of $530 \times 530 \mu \mathrm{m}^{2}$ was used to obtain elemental distributions tables. Details of the instrumental settings can be found elsewhere [5].

\subsubsection{Atomic force microscopy}

Tapping mode atomic force microscopy (TMAFM) films images were acquired with a Veeco di CP-II System and standard etched silicon probes (nominal spring constant $50 \mathrm{~N} / \mathrm{m}$, resonance frequency $\sim 300 \mathrm{kHz}$ ).

\subsubsection{Scanning electronic microscopy}

LDPE and PE-g-HEMA films were coated with a thin layer of gold under reduced pressure and their scanning electron micrographs were obtained using a JEOL (JSM 5310) scanning electron microscope.

Porous dimension and distribution analysis were made using IMAGE J (V1.36b) software from WCIF (NIHUSA).

\section{Results and discussion}

\subsection{Nuclear microprobe techniques}

In spite of different nuclear microprobe techniques have been used, in this section only data from PIXE will be discussed since analysis of the RBS and STIM data is still ongoing.

Proton irradiation of samples, performed at the nuclear microbe, result in the emission of X-rays characteristics of the chemical elements present in the materials. Under the experimental conditions used for the PIXE experiments [5], it is only possible to detect elements with atomic number equal or higher than Si. This means

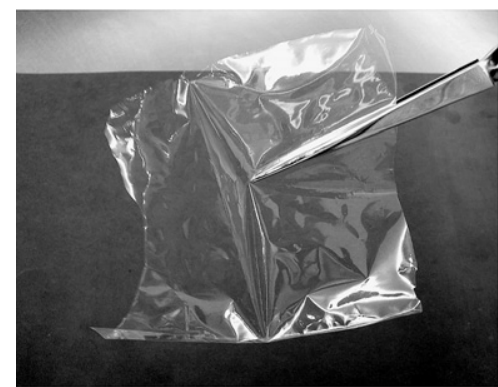

LDPE film matrix (non irradiated)

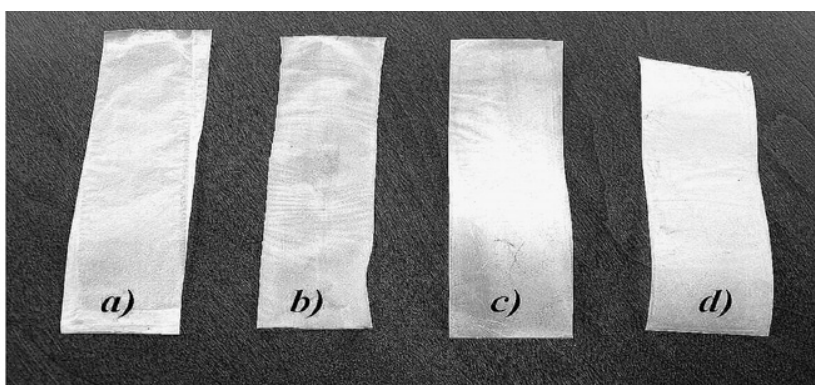

PE-g-HEMA grafted films

[a) $25 \mathrm{~h}, 237 \%$; b) $30 \mathrm{~h}, 403 \%$; c) $35 \mathrm{~h}, 166 \%$; d) $40 \mathrm{~h}, 163 \%$ ]

Fig. 1. Analyzed films. copolymeric films are presented in their final standard analysis format $\left(8 \times 2 \mathrm{~cm}^{2}\right)$. 
that, even though being unable to give information about the thirteen chemical elements lighter than $\mathrm{Si}$, the technique is sensitive to the elements that can be the most effectively toxic contaminants of a biomaterial (metals and transition metals).

Quantitative analysis performed on the PIXE data is shown in Table 1 . The results refer to a $530 \times 530 \mu \mathrm{m}^{2}$ scanning area for each sample.

The results show traces of impurity contaminations $(\mathrm{Si}$, $\mathrm{P}, \mathrm{S}, \mathrm{Cl}, \mathrm{K}, \mathrm{Ca}, \mathrm{Ti}, \mathrm{Fe}$ and $\mathrm{Zn}$ ) in the LDPE film matrix and in the copolymeric films prepared, although their concentrations do not pose human toxicological risk [6-10]. The concentrations found are of ppm $\left(\mu \mathrm{g} \mathrm{g}^{-1}\right)$ order, and it was observed a reduction in $\mathrm{Cl}, \mathrm{K}$ and $\mathrm{Ca}$ concentration, a part from a film $(25 \mathrm{~h}, 237 \%)$, relatively to those found in the LDPE film matrix.

$\mathrm{P}, \mathrm{Cl}, \mathrm{K}$ and $\mathrm{Ca}$ are elements which are needed in the human diet in amounts of $100 \mathrm{mg}$ or more each day [7]. Phosphorus was only detected in the film matrix $\left(72 \pm 27 \mu \mathrm{g} \mathrm{g}^{-1}\right)$, and the highest concentration of $\mathrm{Cl}, \mathrm{K}$ and $\mathrm{Ca}$ found in the copolymeric films were $171 \pm 3$, $31 \pm 2$ and $159 \pm 2 \mu \mathrm{g} \mathrm{g}^{-1}$ respectively.

$\mathrm{Si}, \mathrm{Fe}$ and $\mathrm{Zn}$ are elements which the human body requires in very small quantities, generally less than $100 \mathrm{mg} /$ day [7]. Silicon is non-toxic as element and in all its natural forms, namely silica and silicates, which are the most abundant. The only way, medically reported, that silicon may cause diseases is by inhalation in great quantities of crystalline silica (silicon dioxide) dust (e.g. miners and stonecutters). In that case it is a potent respiratory hazard $(\mathrm{LD} 50($ oral $)=3160 \mathrm{mg} / \mathrm{kg} \mathrm{bw})$ resulting in a serious lung disease known as silicosis [8]. In our case the most silicon contaminated copolymeric film shows a concentration of $752 \pm 30 \mu \mathrm{g} \mathrm{g}^{-1}$.

Humans might experience iron toxicity above $20 \mathrm{mg} / \mathrm{kg}$ bw, and $60 \mathrm{mg} / \mathrm{kg}$ bw is a lethal dose [9], though our most iron contaminated film shows a value of $18 \pm 1 \mu \mathrm{g} \mathrm{g}^{-1}$. For zinc the higher concentration found in the new films is $51 \pm 4 \mu \mathrm{g} \mathrm{g}^{-1}$, and it is reported that evidences of adverse effects in health appears with intakes of $100-300 \mathrm{mg} /$ day [10].

Elemental sulphur is not toxic and is an essential component of all living cells. It is especially important for humans because of its role in protein metabolisms [8]. In our samples only one copolymeric film shows a contamination of $16 \pm 5 \mathrm{\mu g} \mathrm{g}^{-1}$ of $\mathrm{S}$, value that can be disregarded.
Titanium was detected only in one the new films with a concentration of $2 \pm 1 \mu \mathrm{g} \mathrm{g}^{-1}$. Ti is not a poison metal and the human body can tolerate it in large doses being one of the elected materials for hard body implants [6].

The contaminants present in the PE-g-HEMA films that are not present in the LDPE matrix ( $\mathrm{S}$, Ti and $\mathrm{Zn})$, were identified to come from the reagents used during the preparation of the copolymeric films. However it can not be directly related with the grafting degree since there are some oscillations in the concentration of the elements identified in the copolymeric films. This fact suggests that, during the grafting process, some impurities may become trapped. The effectiveness of the purification stage to remove them will depend on the specific position where trapping occurs and of the specific polymeric network environment surrounding it.

Data obtained from the RBS and STIM techniques are expected to help to clarifying this issue. Thickness/density maps as well as impurity distribution maps will be the object of a forthcoming paper.

\subsection{Topographic analysis}

\subsubsection{Atomic force microscopy}

AFM micrographs (Fig. 2) show that, while the LDPE matrix presents a quite flat and smooth surface, the prepared films show a rough surface. The estimated roughness (peak-valley) for LDPE matrix is about $5 \mathrm{~nm}$ (evidence of nanoscale structure at surface), and vary from $7.56 \mu \mathrm{m}$ to $6.03 \mu \mathrm{m}$ in the copolymeric films.

The films grafted at $243 \%\left(t_{\text {irrad. }}=25 \mathrm{~h}\right)$ and $403 \%$ $\left(t_{\text {irrad. }}=30 \mathrm{~h}\right)$ show a surface with broad peaks and valleys, suggesting the presence of a dense grafted layer. In opposition, the films grafted at $166 \%\left(t_{\text {irrad. }}=35 \mathrm{~h}\right)$ and $163 \%$ $\left(t_{\text {irrad. }}=40 \mathrm{~h}\right)$ show a sharp peak-valley surface.

In earlier studies, it was observed that the grafting yield goes through a clear maximum at a certain irradiation dose, after which begins to decrease with the increase of total absorbed dose, even with a bulk monomer concentration enough to carry-over the grafting reaction. It was suggested that this happens as result of the destructive effect of gamma radiation, for doses above the maximum grafting yield over polyHEMA branches grafted onto LDPE surface [3]. Judging from the morphology revealed by AFM images (Fig. 2(d) and (e)), this partial destructive effect, that dominates over the chain linking process, works like

Table 1

Average impurities concentration values found in the analyzed samples $\left(\mu \mathrm{g} \mathrm{g}^{-1}\right)$

\begin{tabular}{|c|c|c|c|c|c|c|c|c|c|}
\hline \multirow[t]{2}{*}{ Material } & \multicolumn{9}{|c|}{ Impurities } \\
\hline & $\mathrm{Si}$ & $\mathrm{P}$ & $\mathrm{S}$ & $\mathrm{Cl}$ & $\mathrm{K}$ & $\mathrm{Ca}$ & $\mathrm{Ti}$ & $\mathrm{Fe}$ & $\mathrm{Zn}$ \\
\hline LDPE matrix & $324 \pm 84$ & $72 \pm 27$ & - & $236 \pm 12$ & $77 \pm 9$ & $148 \pm 7$ & - & $7 \pm 4$ & - \\
\hline Film $(30 \mathrm{~h}, 403 \%)$ & $394 \pm 39$ & - & $16 \pm 5$ & $171 \pm 3$ & $18 \pm 2$ & $20 \pm 21$ & - & $2 \pm 1$ & $51 \pm 4$ \\
\hline Film $(35 \mathrm{~h}, 166 \%)$ & $752 \pm 30$ & - & - & $71 \pm 3$ & $31 \pm 2$ & $56 \pm 1$ & - & $18 \pm 1$ & $21 \pm 2$ \\
\hline Film $(40 \mathrm{~h}, 163 \%)$ & $528 \pm 37$ & - & - & $25 \pm 3$ & $5 \pm 21$ & $56 \pm 2$ & $2 \pm 1$ & - & $19 \pm 2$ \\
\hline
\end{tabular}



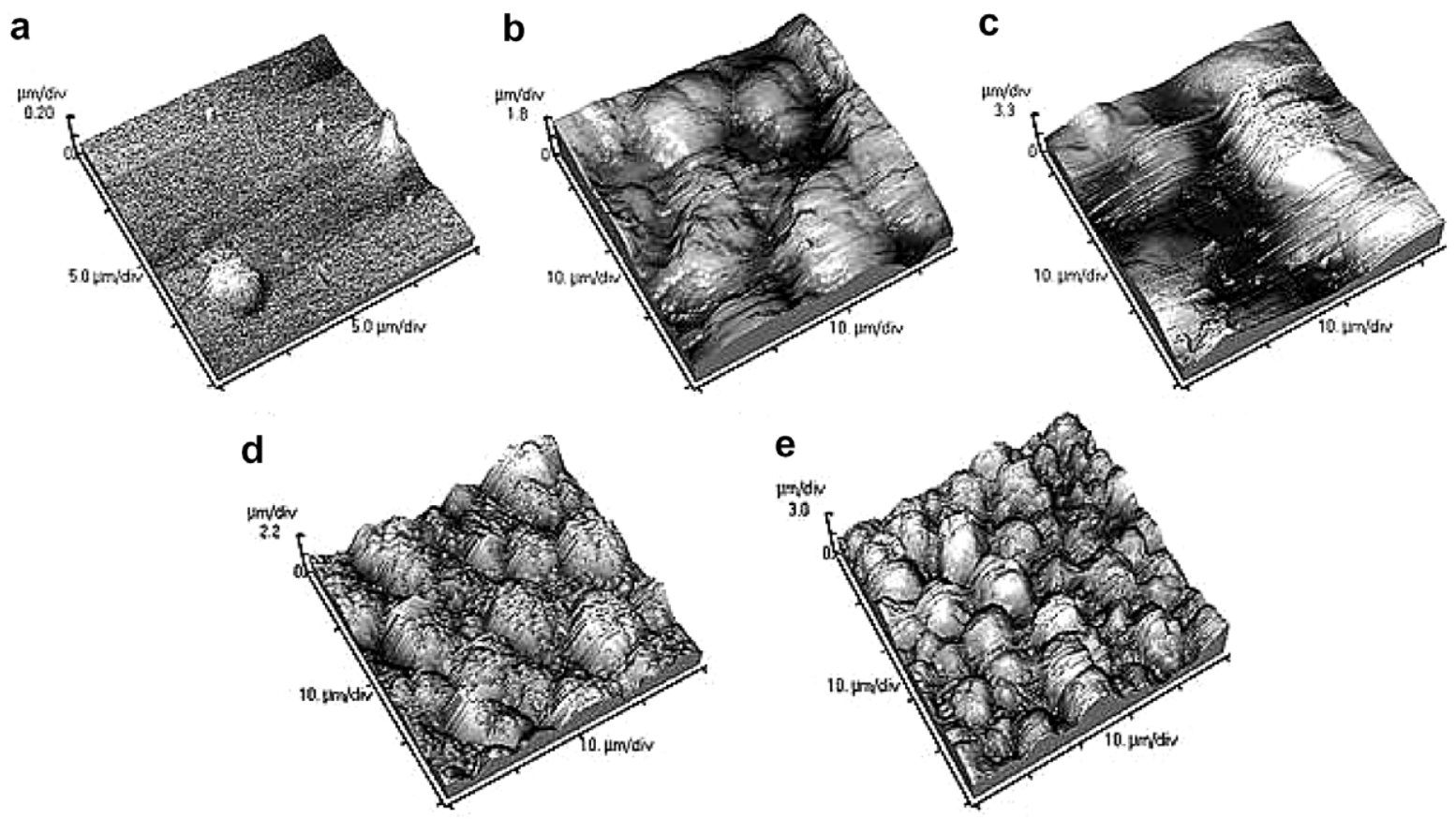

Fig. 2. Topographic 3D projection of films surface. (a) LDPE film (scanned area: $20 \times 20 \mu \mathrm{m}^{2}$ ); (b) PE-g-HEMA film - $25 \mathrm{~h}, 237 \%$ (scanned area: $35 \times 35 \mu^{2}$ ); (c) PE-g-HEMA film - $30 \mathrm{~h}, 403 \%$ (scanned area: $33 \times 33 \mu \mathrm{m}^{2}$ ); (d) PE-g-HEMA film - $35 \mathrm{~h}, 166 \%\left(40 \times 40 \mu \mathrm{m}^{2}\right)$; (e) PE-g-HEMA film $40 \mathrm{~h}, 163 \%$ (scanned area: $50 \times 50 \mu^{2}$ ).

an abrasive tool, leading to a thinner film with a very homogeneous rough surface.

Roughness observed in the copolymeric films make them very interesting and promising for bioapplications. Peaks and valleys define a surface adequate for bio-interaction for cell adhesion and/or proliferation, and physical or chemical immobilization of active biomolecules (enzymes, drugs, thromboresistant agents, etc.) [2].

\subsubsection{Scanning electronic microscopy}

SEM micrographs showing the surface morphology of the films are presented in Fig. 3. LDPE film micrograph show that it has a quite flat surface, confirming AFM results. The images obtained from the new material reveal the porous structure resulting from the graft process. It may be observed the existence of rounded blocks, at different levels of profundity, linked by filaments of different thicknesses that depend on radiation dose (or grafting yield), forming a 3D porous network.

Whereas the lower grafted films shows large porous paths at the upper surface level, the highest grafted film show an obstructed porous surface structure with dense rounded polymeric aggregates.

The high grafted film (403\%) seems to suffer a porous agglutination process as a result of the high yield of graft. This process leads to a partial blockage of the porous surface structure with the consequent reduction of its hydration capacity. In fact, in previous hydration studies [3,4], it was observed that the maximum hydration capacity (up to $95 \%$ ) does not correspond to the highest grafted film but to films grafted at $\sim 230-250 \%(\sim 20-25 \mathrm{~h}$ of irradiation). The film grafted at $403 \%$ (30 h of irradiation) only reaches a hydration level of $45 \%$. The films irradiated during $35 \mathrm{~h}(166 \%)$ and $40 \mathrm{~h}(163 \%)$, present a hydration

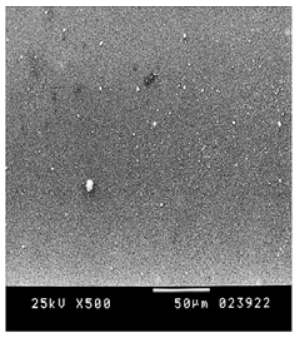

LDPE film matrix (non irradiated)

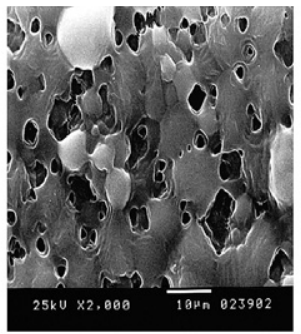

PE-g-HEMA film $(25 \mathrm{~h} ; 237 \%)$

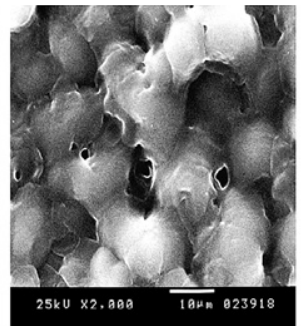

PE-g-HEMA film

$(30 \mathrm{~h} ; 403 \%)$

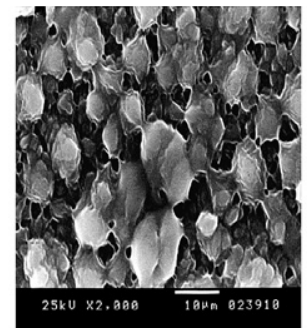

PE-g-HEMA film (35h; 166\%)

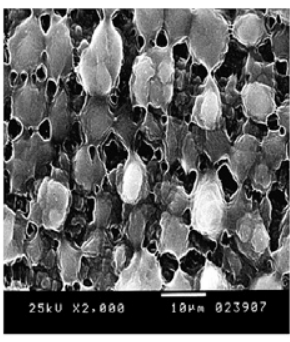

PE-g-HEMA film

$(40 \mathrm{~h} ; 163 \%)$

Fig. 3. SEM micrographs of LDPE film (500×) and PE-g-HEMA copolymeric films (2000×). 


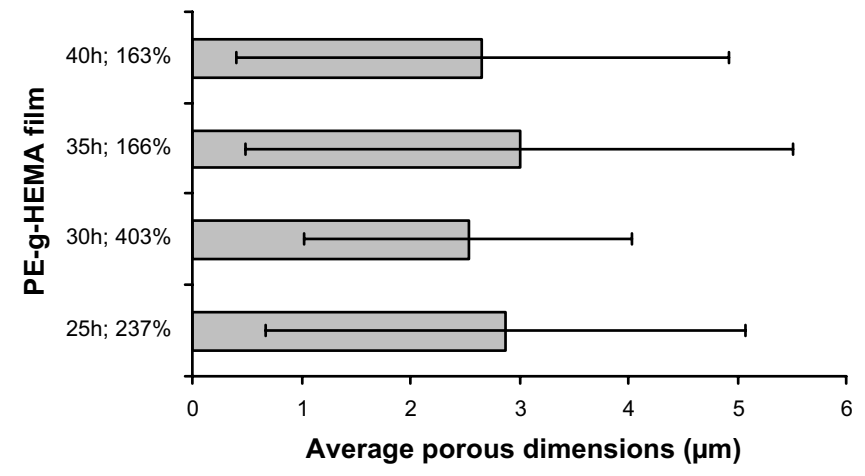

Fig. 4. Average porous dimensions found in LDPE copolymeric films; (bars represent the dimensions range observed in each sample).

capacity of $25 \%$ and $20 \%$, respectively. The observed average porous dimensions and length spread is in agreement with this behavior (Fig. 4). It can be seen that the high grafted film presents the lower values. The films grafted at $166 \%$ and $163 \%$, although presenting good porosity are thinner in consequence of the destructive effect of gamma irradiation, and cannot reach the hydration levels obtained with $20-25 \mathrm{~h}$ of irradiation.

This behavior can now be better understood based on morphological analysis obtained by SEM.

The influence of the porous structure on hydration/ dehydration kinetics of the grafted films will be addressed in a forthcoming work.

\section{Conclusions}

Obtained results evidence that the experimental protocol developed and optimized to prepare these new copolymeric films is effective. Data collected also shows that the external fonts of film contamination are controlled and that the final purification stage leads to a general contamination reduction relatively to that found in the initial LDPE film used as backbone. The result is a final material with nontoxicological risk.

The films surface roughness revealed by AFM technique meets one of the essential conditions required for bio-inter- action and the 3D porous structure of the copolymeric films observed by SEM allowed a better understanding of the hydrophilic behavior already observed in previous work.

To sum up it can be said that the disorder promoted in the molecular structure of the LDPE film by the gamma irradiation grafting process tailored its surface, improving the diffusion coefficients of other species deep inside the polymeric matrix and increasing the hydrophilic properties of the material. In other words, the surface morphological features of the grafted polyHEMA layer onto LDPE film leads to a new LDPE copolymeric based material very promising for multiple bioapplications.

\section{Acknowledgements}

The authors wish to acknowledge L.C. Alves and C.P. Marques from ITN Physics Department, for NM (PIXE) and AFM measurements, and to P. Alves from University of Coimbra, for SEM images.

\section{References}

[1] R.S. Benson, Nucl. Instr. and Meth. B 191 (2002) 752.

[2] Karen J.L. Burg, Scott Porter, James F. Kellam, Biomaterials 21 (2000) 2347.

[3] L.M. Ferreira, A.N. Falcão, M.H. Gil, Nucl. Instr. and Meth. B 236 (2005) 513.

[4] L.M. Ferreira, A.N. Falcão, M.H. Gil, Mat. Sci. Forum 514-516 (2006) 1034.

[5] L.C. Alves, M.B.H. Breese, E. Alves, A. Paul, M.R. da Silva, M.F. da Silva, J.C. Soares, Nucl. Instr. and Meth. B 161-163 (2000) 334.

[6] H.G. Seiler, A. Sigel, H. Sigel, in: Handbook on Metals in Clinical and Analytical Chemistry, Marcel Dekker Inc., New York, 1994.

[7] E. Hodgson, in: A Textbook of Modern Toxicology, third ed., Wiley Interscience - John Wiley and Sons publications, New Jersey, 2004.

[8] R.R. Lauwerys, P. Hoet, in: Industrial Chemical Exposure Guidelines for Biological Monitoring, second ed., Lewis Publishers, New York, 1993.

[9] C.D. Klaassen, M.O. Amdur, J. Doull, in: Casarett and Doull's Toxicology - The Basic Science of Poisons, third ed., Macmillan Publishing Company, New York, 1986.

[10] G.F. Fosmire, Zinc toxicity, Am. J. Clin. Nutr. 51 (1990) 225. 